\title{
Automatic Life Saving Device Using Feedback Control System in Commercial Aircrafts
}

\author{
http://dx.doi.org/10.3991/ijoe.v7i4.1710 \\ Tennyson Samuel John \\ Velammal Engineering College, Anna University, Chennai, India
}

\begin{abstract}
Several safety devices have filled in the vacuous spaces in commercial airplanes which once did not possess such sophisticated mechanisms. Commercial airplanes have copious amount of instruments and electrical circuits to provide a proper control system inside the plane. A noteworthy invention in the early 80's is the oxygen masks provided for every passenger during a plane crash or if the airplane is subjected to climatic disturbances while travelling a passenger manually uses the oxygen masks. The oxygen control system in the airplanes has proved very effective in providing an overall safety to the passengers. But the technique given below is far more advanced than the present scenario.
\end{abstract}

Index Terms-Aircraft, $\mathrm{CO} 2$ analyzer, Feedback control system, Instrumentation.

\section{INTRODUCTION}

A person suffering from a breathing ailment is succumbed to variations in the carbon dioxide levels. Thereby this CO2 is measured and using a feedback control loop quick actions can be taken in order to provide quick aid to the ailing patient. These are completely automatic and hence it is advanced than the manual oxygen control system. At the end of the day saving a life iswhat a humanistic approach is all about. Here several techniques used in instrumentation are put to use such as digital signal processing, embedded system, and bio-medical instrumentation and most importantly the core technique is the control systems. Simultaneously two control actions take place depending on the error signal e (t).

Medically it has been proven that breathing difficulties or shortness of breath lead to several cardiac diseases or in some extreme cases heart attack. This is a typical example of process control too. Here a process is being controlled inside an aircraft. This technique if implemented would make commercial aircraft safety systems achieve a new feat and close in on the pinnacle of excellence. Ultimately a life is saved in the time which is elapsed while using the conventional technique. It is of a great worth!!!

\section{PRINCIPLE}

In this technique the fundamental principle used is the feedback control action. Here, automatically $\mathrm{O} 2$ is supplied using special designs around the seat facing the passenger (to be designed while building the aircraft).The oxygen is supplied temporarily ill the cabin crew attends to the suffering person. This time gap may be for few seconds. The error signal e $(\mathrm{t})$ triggers the alarm in the CCAS and thereby calling in for immediateaction. A simple relation is arrived at between $\mathrm{CO} 2$ levels and $\mathrm{O} 2$ lev- els. Supplying excess $\mathrm{O} 2$ temporarily will allow the person inhale some more as his rate of $\mathrm{O} 2$ intake would increase.

\section{CONTROL ACTION AND PROCESS CONTROL}

The feedback control loop is shown below. A feed forward loop cannot be used in this technique as measurement of the disturbance is tedious process and is a trivial process under such circumstances.

The transducer or a sensor unit comprises of a $\mathrm{CO} 2$ analyzers which are provided with sensors. A Model 906 analyzer is one such high precision type analyzer which can be used. The sensor detects the amount of $\mathrm{CO} 2$ levels from the passengers which are exhaled out. A separate $\mathrm{CO} 2$ analyzer unit is provided for determining the CO2 level inside the aircraft at std.atmospheric pressure and temperature (set point).

The CO2 levels measured from the person are compared with the set point value and thereby an error signal is generated $\mathrm{e}(\mathrm{t})$.Depending on the deviation of the $\mathrm{e}(\mathrm{t})$ the PID controller with a pneumatic actuator and control valve is provided for the control action to vary the control signal given to the $\mathrm{O} 2$ supply depending on the deviation of the $\mathrm{e}(\mathrm{t})$.

Simultaneously using DSP or Embedded system software is developed in such a way that If $(e(t) !=0)$, the alarm is triggered. The signal is sent to CCAS or Cabin crew alerting system wherein the alarm is goes off notifying the cockpit and cabin crew. Level 3 alarm is assigned for this technique in the airplane. This alarm is generally used in case of plane crash or if the plane is about to plunge into the sea. It is the highest level of alarm in an aircraft.

The $\mathrm{O} 2$ is supplied to the passenger for a certain period of time using a Schmitt trigger and timer circuit. The time period for the control action to be performed can be varied depending on the quantity of $\mathrm{O} 2$ to be supplied temporarily. The PID controller has several advantages as it combines the features of proportional derivative and integral controllers. Its control output equation is given as:

$P=K p \cdot E p+K p \cdot K i \cdot \int_{0}^{t} E p \cdot d t+K p \cdot K d \cdot \frac{d E p}{d t}+P i(0) ;$

Here $\mathrm{p}=$ controller output; $\mathrm{E}(\mathrm{t})$ or $\mathrm{Ep}=\mathrm{error}$ signal; $\mathrm{Kp}, \mathrm{Kd}, \mathrm{Ki}$ are PID gain values or parameters. Pi (0) is the initial integral controller output.

It is to be noted that the controller should be tuned before putting it into use. Either the Z-N tuning method can be adapted or the Cohen Coon method can be used. 


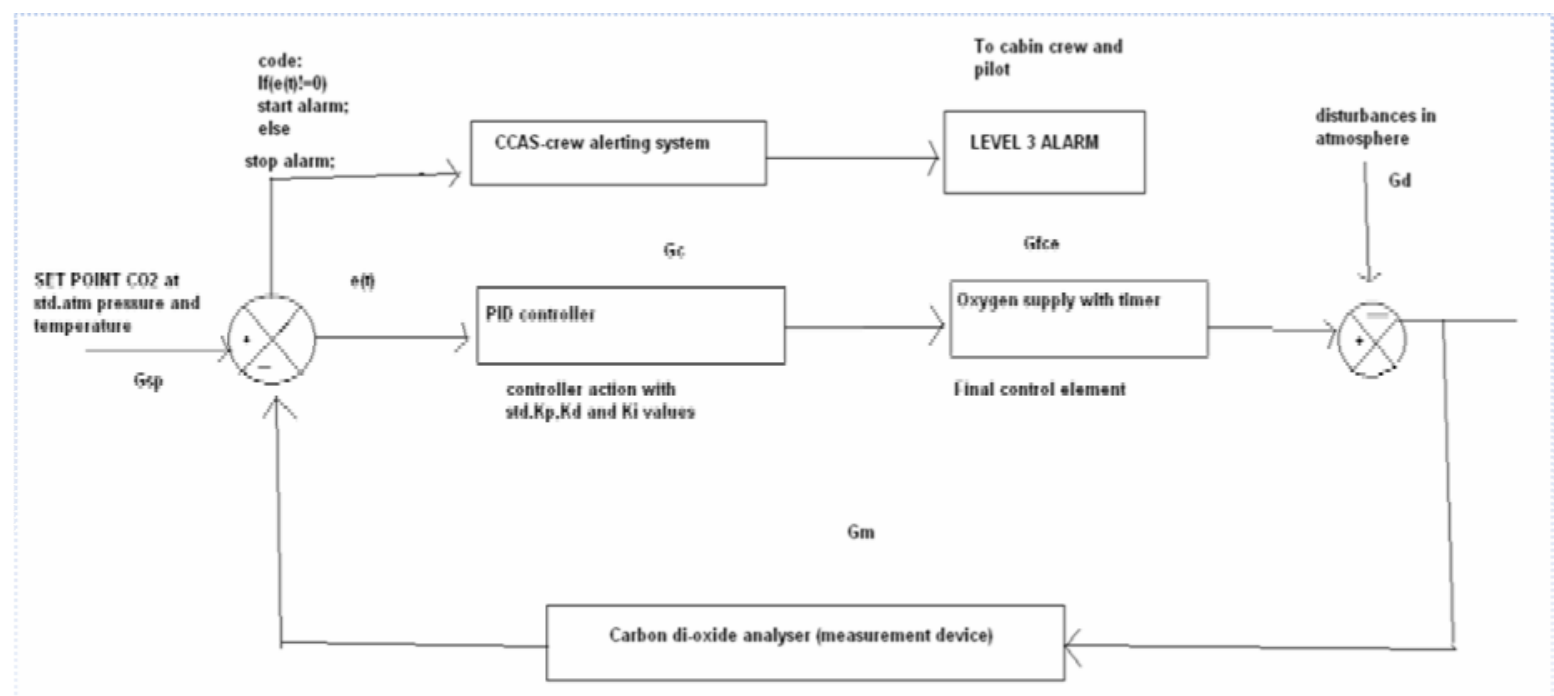

Figure 1. Feedback action used in ALSD in airplanes

The controller parameters are given as follows:

$$
\begin{aligned}
& K p=\frac{t}{t d}\left[\left(\frac{4}{3}\right)+\frac{t d}{4 t}\right] \\
& T i=t d\left[\frac{\left(32+\left(\frac{6 t d}{t}\right)\right)}{13+\left(\frac{8 t d}{t}\right)}\right] \\
& T d=t d\left[\frac{4}{\left(11+2 \frac{t d}{t}\right)}\right]
\end{aligned}
$$

Here $\mathrm{t}=$ =time constant; $\mathrm{td}=$ dead time; $\mathrm{Ti}=$ Integral time; $\mathrm{Td}=$ derivative time;

Figure 1 represents the control loop used inside the aircraft in order to achieve higher efficiency and output. It is observed that a process is being controlled using a feedback network.

\section{OPERATION}

The simplifiedblock diagram representation of the process occurring is shown below. It is evident from the diagram that $\mathrm{CO} 2$ measured from a diseased person who is travelling is directly compared with the standard value of CO2.Thereby generating an error signal. The oxygen supply with a timer supplies oxygen at a certain pressure level which is kept at the maximum in order to provide maximum aid. This is carried outas a cyclic process. Oxygen supply and timer act as the final control element. It is to be noted that from figure 1 , disturbances are also to be taken into account.

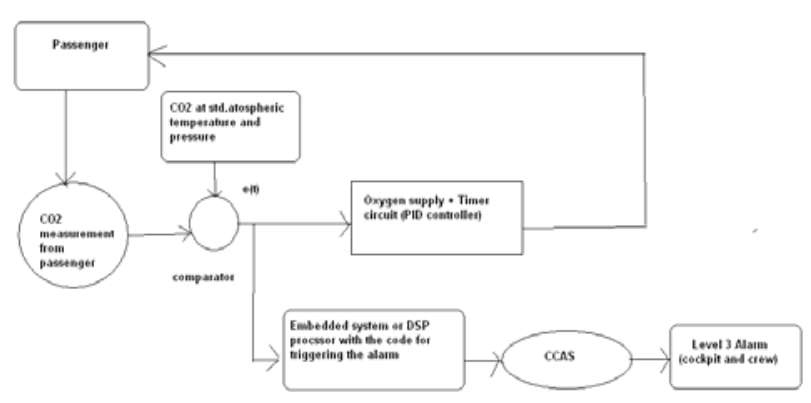

Figure 2. Block Diagram of the Operation
These disturbances may correspond to the other gases mixed in the atmosphere. The Volume of air should be taken into account and the volume of $\mathrm{CO} 2$ is to be subtracted from it in order to obtain the volume of the other gases. It is to be noted that the $\mathrm{CO} 2$ analyzer unit will not detect any gas other than CO2.Hence it is only for the theoretical use do we need to calculate volume of the other gases.

There are surplus amount of Oxygen supply systems available in the market at present. They range from the sophisticated systems used in the Hospitals to the masks used while flying above $25000 \mathrm{ft}$ in the fighter planes. But for the commercial aircraft the most suitable one would be the Oxygen systems used in the hospitals. As the oxygen can be easily delivered through long channels across every seat. Also the unit can be placed near the cabin crew so that the pressure levels can either manually be controlled or automatically regulated. One should also consider the partial pressure ofO2 for this process along with the cabin pressure. As the altitude increases the pressure inside the cabin decreases. Hence the cabin pressure is incremented in order to keep thepartial pressure of $\mathrm{O} 2$ constant at $18.40 \mathrm{kPa}$.Cabin pressure is controlled by outflow valves and safety valves (controlled by redundant electric motors) to keep cabin pressure above $75 \mathrm{kPa}$ (equivalent to $2400 \mathrm{~m}$ altitude), and never below $5 \mathrm{kPa}$ under pressure or $500 \mathrm{kPa}$ overpressure to outside air. In order to throw more light on the topic let's look at an example given below.

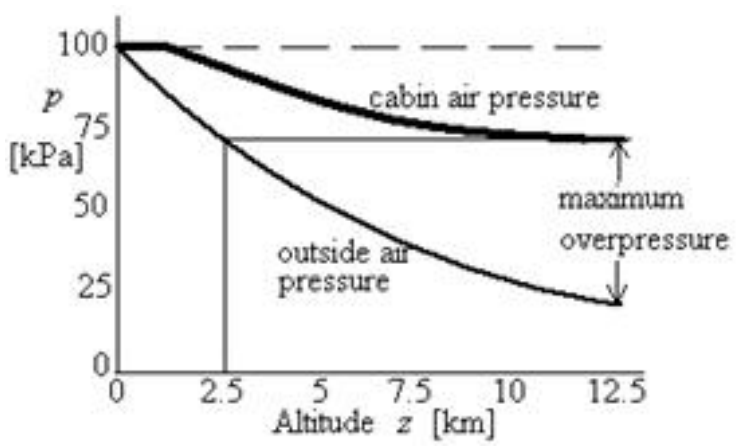

Figure 3. Variation of pressure with altitude 
Let us assume the volume of $\mathrm{O} 2$ in air as $\mathbf{1 0 , 0 0 0}$ ppm.Generally in order to determine the amount of oxygen intake the TLC (Total Lung Capacity) has to be considered.

$$
T L C=\operatorname{Vol}\left(O_{2}\right) * \frac{d T L C}{d \operatorname{Vol}\left(O_{2}\right)}
$$

TLC $=2000$ ppm (assumption) $=20 \%$ of Vol (O2)

The above given TLC value represents for an individual who is salubrious and lacking shortness of breath. The lung capacity for that person is 2000ppm.Now, let's consider this person is suffering from breathing difficulties and shortness of breath.Eventhough he has a capacity of 2000ppm; he is unable to take in $\mathrm{O} 2$ and fill the entire volume of lungs.

Due to shortness of breath, Vol (O2) at intake $=1000 \mathrm{ppm}=10 \%$ of $\mathrm{Vol}(\mathrm{O} 2)$; It is to be noted here that when a person takes in $\mathrm{O} 2$ he exhales out the same amount of $\mathrm{CO} 2$. Both the volumes are the same as it is a cyclic process the $\mathrm{O} 2$ enters and $\mathrm{CO} 2$ exits. Therefore, Vol $(C O 2)=1000$ ppm;

The standard or average measured value of CO2 available in the closed aircraft is assumed to be as $2000 \mathrm{ppm}$ or more. Say, it is $2500 \mathrm{ppm}$. The deviation from the set point of the Vol (CO2) is 1500 ppm (Set point $=2500$ ppm)

S.P-Vol $(C O 2)=2500 \mathrm{ppm}-1000 \mathrm{ppm}=1500 \mathrm{ppm}$;

The $1500 \mathrm{ppm}$ deviation is the $\mathrm{e}(\mathrm{t})$ value or magnitude. Once the e(t) value is not equal to zero, the level 3 alarm goes ON automatically. The alarm is indicated with red LED's glowing provided with a chime sound ringing continuously. It is observed in the CCAS panel. The error signal is converted to a pressure value using a I-P converter and this is given as input to the actuator which acts on the control valve. The PID controller action is carried out here. Depending upon deviation amount the final control element is opened i.e., the necessary amount of $\mathrm{O} 2$ is supplied. One can also increase the $\mathrm{O} 2$ amount manually. In this way only the valve for $\mathrm{O} 2$ supply is either opened or closed. Hence a constant amount of $\mathrm{O} 2$ can be supplied for few minutes till the passenger is attended. The pressure of $\mathrm{O} 2$ sent can be varied manually. When used automatically, the deviation can be multiplied with a multiplication factor and then converted as a pressure signal in order to provide excess $\mathrm{O} 2$ around the person till the timer goes OFF. Hence the process gets repeated as long as the $\mathrm{e}(\mathrm{t})=0$. The most aptly used CO2 analyzerunit is the MODEL 906 analyzer from Quantek instruments. The specifications and features of various components are explained below.

\section{MODEL 906 CO2 ANALYZERS FROM QUANTEK INSTRUMENTS}

\section{A. Overview}

The Model 906 Carbon Dioxide Analyzer is designedfor continuous or spot check monitoring of $\mathrm{CO}_{2}$ levels in all types of processes, gas blending, biotech and other systems. The Model 906 is available with any range from 0 to $1 \%$ up to 0 to $100 \%$ vol/vol full scale. Options include battery operation, analog outputs, internal sample pump and a sensor remotely mounted from the base unit.

\section{B. Features}

- Ranges of $1,10,30$, and 0 to $100 \%$ carbon dioxide

- AC or battery operation

- Internal sampling pump

- Economically priced

- 0-5 Vdc analog outputs and data logging available

\section{Sensor Design}

The Model 906 uses a solid-state infrared sensor which has no moving parts, a compact optical cell, and microprocessor-based calibration factors using a 6th order polynomial equation to linearize the full range measurement up to $100 \%$. InfraredCO $\mathrm{C}_{2}$ measurements are inherently non-linear, especially over a high range of concentrations. The math algorithm used in the 906 yields more accurate results over a much wider range of concentrations than other methods.

The Model 906 sensor combines cutting edge 32 bit digital signal processing with the solid reliability, compact size and state of the art microprocessor technology that makes this full-featured $\mathrm{CO}_{2}$ measurement system less complex and more robust than other instrumentation. Its reliability is backed it up with a two year warranty, twice the industry standard. The advanced design allows an output requiring less frequent calibration. It provides a stable, drift-free linearized voltage or current output that is much less susceptible to external electro-magnetic interference than conventional analog electronics.

The sensor assembly is cable connected to the control circuit board. It can be used with diffusion or pumped sample draw systems. The measurement accuracy is not affected by sample flow rate.

\section{Sampling versatility}

The sensor design is compact, has a low internal volume and requires only a low sample flow of about 10 to $100 \mathrm{cc} / \mathrm{min}$. The sample should be clean and dry (noncondensing). Moisture or dirt deposits on the internal surfaces of the sensor can cause errors in the reading. A disposable type particulate filter can be inserted in the sample line if needed.

Sample flows into the sensor through the front panel fitting and vents out through a port fitting on the back panel. The sensor operates at atmospheric pressure, and the accuracy of the measurement is not dependent on the flow rate of the sample gas. There are no restrictions in the sample cell, and samples introduced at slightly higher pressure will quickly equilibrate to atmospheric pressure. For those systems where a source of sample flow is not available, the Model 906 can be equipped with an optional internal miniature diaphragm pump with an on-off switch on the front panel, or the compact sensor head can be mounted directly in the system to be measured and connected via cable to the analyzer. In the latter case, sample diffuses into the sensor through port openings in the sensor body.

\section{E. Battery Operation}

With its low power requirement, the Model 906 can be operated with an optional battery for those applications where AC power is not readily available, or for convenience if spot checking samples at different locations. Atotally sealed, long-life internal $12 \mathrm{~V}$ dc gel battery acceptsa full or partial charging cycle and will operate the 


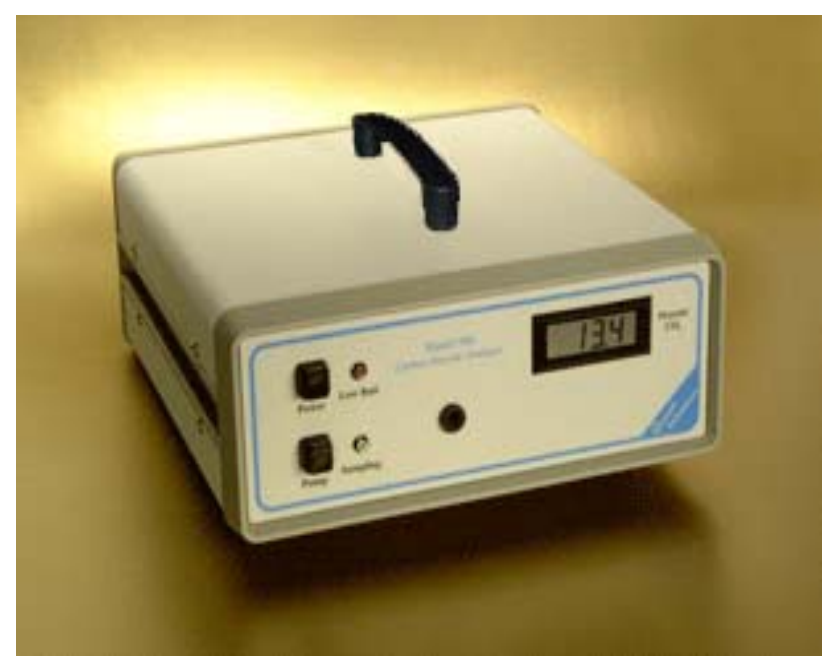

Figure 4. The Model 906 can have the sensor located remotely up to a distance of 2-3 feet from the unit.

unit for up to 8 hours. The charger module plugs into a standard 115 or 230 Vac outlet for charging or continuous operation. Alternatively, the unit can be powered from an external 12-24 Vdc source.

As the sensor can be used at $\mathbf{2 - 3} \mathbf{~ f t}$ from unit it is most likely to be wired to the seat where the passengers are seated. It should be designed in such a way that it has a high resolution. A special feature about $\mathrm{CO} 2$ analyzers is that they do not analyze other gases.

\section{CONCLUSION}

This technique if implemented would increase the passenger comfort ability and safety. This device can also be used in Cruises and submarines.Consequently,the space shuttles can be provide $d$ with a similar technique and the information continually transmitted to the station on earth. The overall safety of passengers or the people travelling is the core importance. We can be looking at a new revolution in science, engineering and technology.

\section{REFERENCES}

[1] Aircraft systems-Mechanical, electrical and Avionics subsystems Integration -second edition, IanMoir and Allan Seabridge

[2] Aircraft Environmental control from http://webserver.dmt.upm.es/ isidoro/tc3/Aircraft\%20ECS.htm\# Toc233109835

[3] Boeing 737-800 VT-JNJ specifications and features

[4] Chemical process control, George Stephanopoulos.

[5] Control Systems Engineering (fifth edition) by I.J.Nagrath and M.Gopal, New Age International Publishers

[6] Middleton, D.M, et al, (1989), Avionics Systems, Longman Scientific and technical, Harlow

\section{AUTHOR}

Tennyson Samuel John is with Velammal Engineering College, Anna University, Chennai, India.

Received 21 June 2011. Published as resubmitted by the author 26 October 2011. 